\title{
PENGEMBANGAN SISTEM MONITORING KEAMANAN SEPEDA MOTOR BERBASIS INTERNET OF THINGS
}

\author{
Harun Sujadi ${ }^{1}$, Tri Ferga Prasetyo ${ }^{2)}$, Pafsi Paisal ${ }^{3)}$ \\ Program Studi Informatika, Fakultas Teknik, Universitas Majalengka \\ Email : harunsujadi@gmail.com, triferga.prasetyo@gmail.com, pafsip@gmail.com
}

\begin{abstract}
Advances in the field of information technology, we can know about the various technological innovations created to help human life. One of them is the internet of things technology that provides benefits in life among them in monitoring the security. Security is one of human need. One of them is safety on a motorcycle. The number of motorcycles in Indonesia alone is quite a lot. But not yet balanced with adequate security system, so that the theft of motorcycle was still high enough. Many ways that can be done by breaking a burglar motorcycle ignition lock, one of which is by using a special key. In addition, motorcycle theft may occur due to lack of responsiveness to inform the surrounding environment, so thieves can bring a motorcycle freely. So the need for motorcycle security is higher, and motorcycle owners feel safe about the vehicle. This security system using microcontroller components, ultrasonic sensors, PIR sensors and relay integrated with IoT platform that cayenne using internet network mounted on a motorcycle. So that the motorcycle owner is able to monitor the safety of his motorcycle even from long distance as long as there is an internet network connection.
\end{abstract}

Keyword : security system, microcontroller, internet of things

\section{PENDAHULUAN}

Jumlah produksi kendaraan bermotor pada saat ini mencapai jutaan unit. Badan Pusat Statistik (2017) menyatakan bahwa jumlah produksi sepeda motor di Indonesia pada tahun 2016 sebanyak 5931285 unit. Namun sayangnya banyaknya jumlah sepeda motor yang diproduksi oleh Indonesia saat ini belum diimbangi dengan sistem keamanan sepeda motor yang memadai. Akibatnya angka pencurian sepeda motor di Indonesia juga mengalami peningkatan. Badan Pusat Statistik (BPS) mencatat pencurian kendaraan sepeda motor pada 2016 sebesar 37.871 kasus. Di wilayah kabupaten Majalengka sendiri kasus pencurian sepeda motor cukup tinggi. POLRES Majalengka mencatat pada tahun 2017 terdapat 55 kasus pencurian sepeda motor. Berdasarkan keadaan yang demikian, maka perlunya sebuah solusi untuk meminimalisir tindak pencurian sepeda motor yaitu dengan penelitian yang berjudul "Pengembangan Sistem
Monitoring Keamanan Sepeda Motor Berbasis Internet of things". Dimana Sistem keamanan sepeda motor tersebut mampu memberikan infomasi secara realtime serta saling terintegrasi ke dalam smartphone pemilik (user) melalui jaringan internet, supaya sepeda motor tersebut bisa dimonitoring meskipun dengan jarak yang cukup jauh. Selain itu perlu adanya alarm kendaraan pada sepeda motor tersebut untuk memberikan sinyal pemberitahuan kepada lingkungan sekitar ketika sepeda motor tersebut dalam kondisi yang tidak aman. Sehingga lingkungan sekitar mampu mengetahui kondisi sepeda motor dalam kondisi tidak aman.

Berikut merupakan teori-teori yang berhubungan dengan penelitian ini.

a. Sistem Keamanan

Sistem keamanan adalah sistem yang digunakan untuk memberikan rasa aman dan tentram serta bebas dari bahaya ataupun ancaman, sehingga individu tidak merasa

\section{Computer Science | Industrial Engineering | Mechanic Engineering | Civil Engineering}


takut, resah, atau gelisah terhadap barang berharga yang ditinggalkan. sistem keamanan dapat mengetahui kemungkinan adanya tanda-tanda bahaya akan terjadinya tindak pencurian terhadap barang berharga.

b. Internet Of Things

IoT (Internet of Things) adalah sebuah konsep yang bertujuan untuk memperluas manfaat dari konektivitas internet yang tersambung secara terus-menerus. Adapun kemampuan seperti berbagi data, remote control, dan sebagainya, termasuk juga pada benda di dunia nyata. Contohnya bahan pangan, elektronik, koleksi, peralatan apa saja, termasuk benda hidup yang semuanya tersambung ke jaringan local dan global melalui sensor yang tertanam dan selalu aktif.

c. Wemos

Wemos merupakan salah satu modul board yang dapat berfungsi dengan Arduino khususnya untuk project yang mengusung konsep IOT. Wemos dapat running standalone tanpa perlu dihubungkan dengan mikrokontroler, berbeda dengan modul wifi lain yang masih membutuhkan mikrokontroler sebagai pengrontrol atau otak dari rangkaian tersebut, wemos dapat running stand-alone karena didalammnya sudah terdapat CPU yang dapat memprogram melalui serial port atau via OTA serta transfer program secara wireless. (Putri, 2018)

\section{d. Sensor Ultrasonik}

Sensor ultrasonik adalah sebuah sensor yang berfungsi untuk mengubah besaran fisis (bunyi) menjadi besaran listrik dan sebaliknya. Cara kerja sensor ini didasarkan pada prinsip dari pantulan suatu gelombang suara sehingga dapat dipakai untuk menafsirkan eksistensi (jarak) suatu benda dengan frekuensi tertentu. Disebut sebagai sensor ultrasonik karena sensor ini menggunakan gelombang ultrasonik (bunyi ultrasonik). e. Sensor PIR

Sensor PIR (Passive Infra Red) adalah sensor yang digunakan untuk mendeteksi adanya pancaran sinar infra merah dari suatu object. Sensor PIR bersifat pasif, artinya sensor ini tidak memancarkan sinar infra merah tetapi hanya menerima radiasi sinar infra merah dari luar, seperti sensor Infra Red LED (IR LED) dan fotoresistor tetapi hanya menerima radiasi sinar infra merah dari luar. Sensor gerak PIR (Passive Infra Red) adalah sensor yang berfungsi untuk pendeteksi gerakan yang bekerja dengan cara mendeteksi adanya perbedaan/perubahan suhu sekarang dan sebelumnya.

f. Cayenne

Saat ini, platform pengembangan dengan sistem drag-and-drop milik my devices, yaitu Cayenne, menyediakan akses untuk fitur-fitur Arduino saat akan digunakan menjadi board Internet of things alternatif. Cayenne menawarkan layanan cloud yang dapat terkoneksi dengan berbagai macam jenis Arduino dengan variasi shield-nya yang sangat banyak. Selain itu, sebagai fitur unggulan, Cayanne menawarkan kemudahan dalam mengatur, melakukan konfigurasi, dan integrase dengan hanya menggunakan metode drag-and-drop untuk papan pengelolanya. Platform IoT project builder ini juga benar-benar konsen dalam membuat integrasi sistemnya dengan IoT.

Guna mendapatkan hasil penelitian yang optimal harus melakukan kajian dari penelitainpenelitian terdahulu yang linier dengan penelitian ini dapat dijadikan sebagai referensi. Berikut beberapa tinjauan pustaka yang linier dengan penelitian ini :

a. Penelitian yang dilakukan oleh Ika Kholilah, Adnan Rafi Al Tahtawi. pada tahun 2016 dengan judul "Aplikasi Arduino-Android untuk Sistem Keamanan Sepeda Motor". Pada penelitian ini membahas Sistem kemanan sepeda motor ini berbasis relai dan 
akan dikendalikan melalui smartphone dengan sistem operasi Android v4.4 (KitKat) melaui bluethoot. Variable yang terkait dengan penelitian ini yaitu Penggunaan mikrokontroller sebagai media pengontrol sensor dan perangkat lainnya. Perbedaannya adalah penggunakan mikrokontroller, yaitu menggunakan mikrokontroller Wemos D1 yang sudah terintegrasi dengan modul wifi.

b. Penelitian yang dilakukan oleh Harun Sujadi dan Pafsi Paisal pada tahun 2018 dengan judul Prototipe Sistem Keamanan Sepeda Motor menggunakan Mikrokontroller Arduino Uno R3 Dengan Sensor Hc-Sr501 Dan Hc-Sr04. Pada penelitian ini membahas tentang Sistem keamanan sepeda motor berbasis bluethooth dengan menggunakan sensor hc501,hc04, dan acs 712. Dan penggunaan android sebagai alat untuk mengontrol sepeda motor. Variable yang terkait dengan penelitian ini yaitu Indikator keamanan sepeda motor, ketika ada yang akan mencuri sepeda motor. Perbedaanya adalah penggunaan platform cayenne sebagai aplikasi untuk mengontrol keamana sepeda motor.

\section{METODE PENELITIAN}

Pada penelitian ini dilakukan beberapa tahapan yaitu menganalisis kebutuhan sistem, analisis perangkat keras, serta analisis perangkat lunak.

\section{a. Analisis Kebutuhan Sistem}

Tahapan ini bertujuan untuk mengidentifikasi masalah dan kebutuhan spesifik sistem. Kebutuhan spesifik sistem adalah spesifikasi mengenai hal-hal yang akan dilakukan sistem ketika diimplementasikan antara lain : masukan yang diperlukan sistem (input), keluaran yang dihasilkan (output), operasioperasi yang dilakukan (proses), sumber data yang ditangani dan Pengendalian (kontrol).

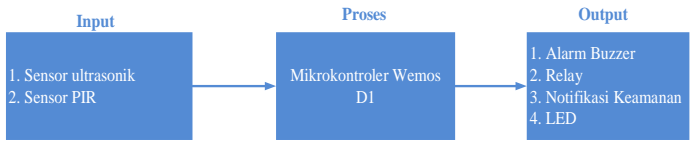

Gambar 1. Blok diagram sistem keamanan

b. Analisis Perangkat Keras

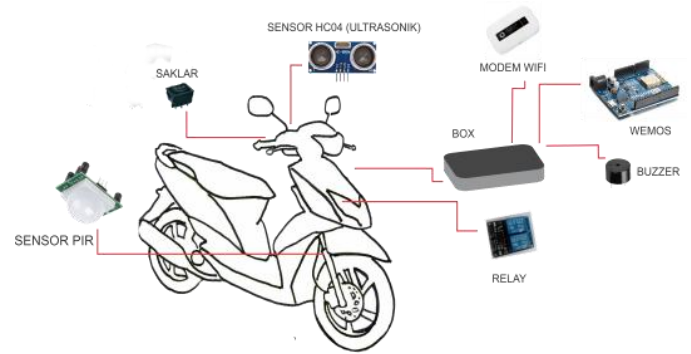

Gambar 2. Perancangan Perangkat Keras

Gambar 2 menunjukkan skema sistem usulan. Dalam rangkaian sistem ini berisi diagram keseluruhan sistem secara garis besar tapi tetap menjelaskan dan menggambarkan cara kerja dari sistem keamanan sepeda motor.

Penjelasan gambar 3 adalah sebagai berikut:

1) Pada ini menggunakan Wemos D1 sebagai pengendali sistem dan sudah ditanamkan program yang mampu mengintegrasikan beberapa perangkat keras dan perangkat lunak.

2) Sensor PIR, dipasang diatas roda depan sepeda motor pada spakboard atas. Untuk mendeteksi putaran roda belakang sepeda motor.

3) Sensor sensor ultrasonik, dipasang didepan dekat setir sepeda motor menghadap kearah belakang. Untuk mendeteksi adanya manusia yang menaiki sepeda motor tersebut.

4) Relay dipasang diantara kunci kontak dengan arus menuju mesin sepeda motor, sehingga bisa memutus arus menuju kunci kontak sepeda motor, dan sepeda motor tidak bisa dinyalakan.

5) Modem Wifi, dipasang sebagai media transmisi data antara rangkaian perangkat lunka dengan aplikasi pada smartphone pemilik sepeda motor.

6) buzzer, dipasang sebagai alarm pemberitahuan jika sepeda motor dalam kondisi tidak aman. 
Pada saat sistem dihidupkan dan sensor pada keamanan sepeda motor lalu menampilkannya di di smartphone berbasis android. Status keamanan sepeda motor di smartphone adalah sebagai berikut:

1) Jika nilai sensor PIR $=0$ pembacaan sensor PIR maka status keamanan aman.

2) Jika nilai sensor PIR $=1$ pembacaan sensor PIR maka status keamanan bahaya.

3) Jika nilai sensor Ultrasonik $>90$ pembacaan sensor Ultrasonik maka status keamanan aman.

4) Jika nilai sensor Ultrasonik <=90 pembacaan sensor Ultrasonik maka status keamanan bahaya.

Tabel 1 Pin-pin I/O Wemos D1

\begin{tabular}{clll}
\hline \hline No & $\begin{array}{l}\text { Nama } \\
\text { Perangkat } \\
\text { Keras }\end{array}$ & $\begin{array}{l}\text { Pin pada } \\
\text { D1 }\end{array}$ & Wemos \\
\hline \hline 1 & Sensor & Digital 4,5 & \\
& ultrasonic & & \\
2 & Sensor PIR & Digital 2 & \\
5 & Buzzer & Digital 1 & \\
6 & Relay & Digital 3 & \\
\hline
\end{tabular}

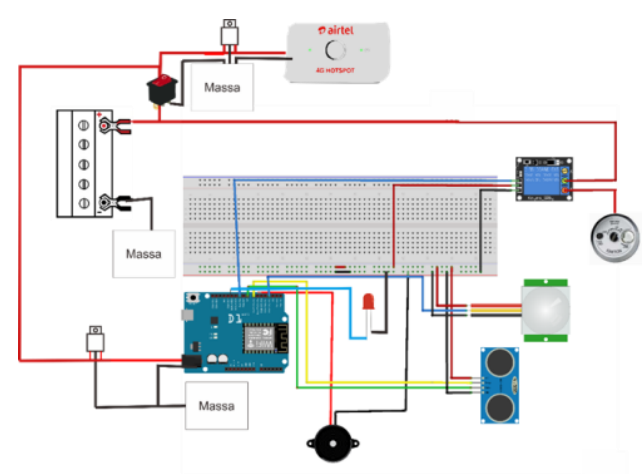

Gambar 3. Rangkaian sistem keamanan

\section{c. Analisis Perangkat Lunak}

Perangkat lunak ini merupakan aplikasi yang digunakan untuk mengontrol sistem keamanan sepeda motor melalui jaringan internet. Pada kali ini menggunakan aplikasi platform IoT yaitu cayenne, diman didalamnya terdapat beberapa fitur yang digunakan untuk mnegontrol keamanan sepeda motor tersebut, diantaranya tobol untuk mengaktifkan sistem, membaca nilai ketika ada yang menaiki sepeda motor, dan ketika ada gerakan / putaran roda sepeda motor. Selain itu pada aplikasi ini memuat trigger ketika ada yang menaiki sepeda motor dan mendorong sepeda motor, maka akan mengirim notifikasi berupa SMS kepeda pemilik sepeda motor.

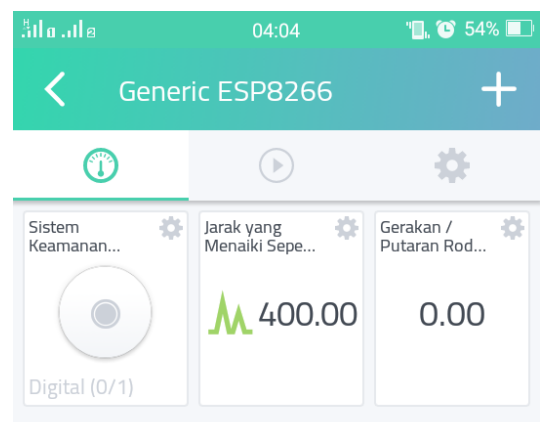

Gambar 3. Tampilan Aplikasi Cayenne

\section{HASIL DAN PEMBAHASAN}

Pada bagian ini membahas mengenai hasil pengujian system yang sudah dilakukan

a. Pengujian Sistem

Pengujian ini dilakukan terhadap Pengembangan Sistem Monitoring Keamanan Sepeda Motor Berbasis Internet Of Things terutama bagian perangkat keras atau sensor yang terlibat dalam sistem tersebut. Pengujian ini bertujuan untuk mengetahui kinerja dari sistem keamanan. Pada pengujian tersebut dilakukan 5 (lima) kali percobaan. Untuk menghitung presentase tingkat keberhasilan digunakan rumus:

$$
\text { Persentase }=\frac{\text { Percobaan Berhasil }}{\text { Banyak Percobaan }} \times 100 \%
$$

\section{Sensor PIR}

Tujuan pengujian dan analisis/pembahasan yang dilakukan pada sensor PIR adalah untuk mendapatkan parameter tentang keakuratan sensor saat mendeteksi gerakan roda sepeda motor.

\section{Computer Science | Industrial Engineering | Mechanic Engineering | Civil Engineering}


Tabel 2 Pengujian Sensor PIR

\begin{tabular}{ccl}
\hline \hline No & Perobaan Ke- & Keberhasilan \\
\hline \hline 1 & 1 & Tidak Sesuai \\
2 & 2 & Sesuai \\
3 & 3 & Sesuai \\
4 & 4 & Tidal Sesuai \\
5 & 5 & Sesuai \\
\hline
\end{tabular}

Berdasarkan pengujian respon sensor PIR yang sudah dilakukan. Dapat ditarik kesimpulan bahwa persentase tingkat keberhasilan dari pengujian sensor PIR adalah $60 \%$.

\section{Sensor Ultrasonik}

Tujuan pengujian dan analisis/pembahasan yang dilakukan pada sensor ultrasonik adalah untuk mendapatkan parameter tentang keakuratan sensor saat mendeteksi jarak manusia ketika menaiki sepeda motor. Dalam pengujian ini dihitung juga dimana untuk Panjang jarak pada penempatan sensor dengan ujung jok sepeda motor sudah ditetapkan yaitu $90 \mathrm{~cm}$.

Tabel 3 Pengujian Sensor Ultrasonik

\begin{tabular}{ccl}
\hline No & $\begin{array}{c}\text { Perobaan } \\
\text { Ke- }\end{array}$ & Keberhasilan \\
\hline 1 & 1 & Tidak Sesuai \\
2 & 2 & Sesuai \\
3 & 3 & Sesuai \\
4 & 4 & Sesuai \\
5 & 5 & Sesuai \\
\hline
\end{tabular}

Berdasarkan pengujian respon sensor ultrasonik yang sudah dilakukan. Dapat ditarik kesimpulan bahwa persentase tingkat keberhasilan dari pengujian sensor ultrasonik adalah $80 \%$.

\section{KeSimpUlan DaN SARAN}

a. Kesimpulan

Berdasarkan hasil pengujian yang telah dirancang dan dibangun, maka kesimpulan penelitian dengan judul "Pengembangan Sistem
Monitoring Keamanan Sepeda Motor Berbasis Internet Of Things" yaitu sebagai berikut :

1. Diantara ketiga sensor tersebut yang digunakan, sensor HC-SR501 atau sensor PIR yang persentase keakuratannya lebih rendah disbanding dengan sensor lainnya, hal itu diakibatkan sensor PIR membaca inputan gerakan yang bekerja dengan cara mendeteksi adanya perbedaan/perubahan suhu sekarang dan sebelumnya.

2. Rata-rata persentase keakuratan kinerja sensor yang digunakan mencapai diatas $85 \%$, sehingga penggunaan sensor-sensor yang digunakan pada sistem keamanan sepeda motor tersebut cukup efektif untuk meminimalisir tindak pencurian sepeda motor.

b. Saran

Pada Pengembangan Sistem Monitoring Keamanan Sepeda Motor Berbasis Internet Of Things masih terdapat kekurangan yang harus dikembangkan untuk meningkatkan kualitas dan nilai fungsionalitasnya.

Adapun beberapa saran untuk pengembangan yang lebih baik yaitu :

1. Penggunaan sensor yang lebih akurat, sehingga sistem keamanan sepeda motor menjadi lebih aman;

2. Penambahan sensor seperti sensor untuk mendeteksi tegangan, supaya ketika ada yang mengaktifkan kunci kontak sepeda motor mampu dideteksi oleh sistem;

3. Penambahan kamera, agar dapat mengetahui situasi dilingkungan sepeda motor;

4. Penggunaan gps untuk melacak posisi sepeda motor;

5. Penambahan modul GSM untuk mengirim pesan notifikasi keamanan sepeda motor berbentuk SMS yang dikirm dari modul GSM, bukan dari platform IoT cayenne.

6. Gunakan kartu perdana dan modem wifi yang kuat sinyal internetnya, agar lebih memudahkan dan mempercepat proses monitoring keamanan sepeda motor.

\section{Computer Science | Industrial Engineering |Mechanic Engineering |Civil Engineering}




\section{REFERENSI}

Yudha Yudhanto. Apa Itu Internet Of Things.

IlmuKomputer.com.2007.

Badan Pusat Statistik. Data Kriminal 2016. Badan Pusat Statistik, Jakarta-Indonesia.

Ika Kholilah, Adnan Rafi Al Tahtawi, (2016), Aplikasi Arduino-Android untuk Sistem Keamanan Sepeda Motor, JTERA Jurnal Teknologi Rekayasa, Vol. 1, No. 1, Hal. 53-58

Mulyanto, Agus. (2009). Sistem Informasi Konsep \& Aplikasi. Yogyakarta : Pustaka Pelajar.

Nazruddin Safaat. (2012) (edisi revisi). Pemrograman Aplikasi Mobile Smartphone dan Tablet PC Berbasis Android. Informatika. Bandung.

Rahmat, R \& Julian, E. (2016). Pengaman Sepeda Motor Berbasis Mikrokontroller. JETri volume 13, Nomor 2.

Sujadi, H., \& Paisal, P. (2018). Sistem Keamanan Sepeda Motor Menggunakan Mikrokontroller Arduino Uno R3 Dengan Sensor Hc-Sr501 Dan Hc-Sr04. Jurnal Ilmiah Teknologi Informasi Terapan, 4(2). 